\title{
Estimating herbage standing crop from rainfall data in Niger
}

\author{
BRUCE K. WYLIE, REX D. PIEPER, AND G. MORRIS SOUTHWARD
}

\begin{abstract}
Authors are quantitative range scientist, professor, Dept. of Animal and Range Science; and professor, Dept. of Experimental Statitics, New Mexico State University, Las Cruces 88003.
\end{abstract}

\begin{abstract}
To help local Niger government authorities and donor countries ameliorate conditions in the advent of drought, a rapid yet simple means to assess annual herbaceous production at the end of the rainy season is needed. Several rainfall variables were tested as estimators of herbaceous production using weighted and logarithmic transformation in regression analysis. A computer program was developed in Basic to generate rainfall parameters from daily rainfall data. Input parameters used to calculate the rainfall variables were varied to minimize the regression standard error of the estimates. Selected regression models were compared using $80 \%$ confidence levels for mean values for each rainfall treatment class using logarithmic and weighted regressions. The selected weighted model involved the number of moist days and consecutive dry days as independent variables. The selected logarithmic model used total rainfall as the only independent variable. These models were tested by comparing an independent data set with the 95\% confidence intervals for observations. Selected models separated rangeland production classes of $200 \mathrm{~kg} \bullet \mathrm{ha}^{-1}$ confidence limits for mean values. The logarithmic model could only do so when biomass levels were less than $800 \bullet \mathrm{ha}^{-1}$. Thus, these models only have application for predicting herbage biomass within rather large classes.
\end{abstract}

Key Words: production models, Sahel, biomass

An African bioclimatic zone where droughts are endemic, called the Sahel, extends east to west across the southern border of the Sahara Desert. The Sahel, roughly $200 \mathrm{~km}$ wide, is delineated by the $150-\mathrm{mm}$ isohyet in the north and the $300-\mathrm{mm}$ isohyet in the south (Justice and Hiernaux 1986). Droughts have devastating effects on national economies and people's livelihoods. Pastoralism contributes to the livelihood of many people in the Sahelian country of Niger, with livestock being second only to uranium in foreign exchange earnings. In Niger, livestock numbers decreased by $50 \%$ during the $84-86$ drought (Onwordi 1989). Attempts at predicting droughts in the Sahel are unreliable. Rather, current drought early warning systems address early identification of drought so government decision makers and donor countries can develop relief strategies (Sollod 1990, Wheeler 1988). A rapid pasture assessment program at the end of the growing season would not only help government annual management and policy decisions, but it would be an important complement to GIS oriented drought early warning systems which combine economic, health and ecological factors (Wheeler 1988). Rainfall data are relatively easy and inexpensive to obtain, and precipitation is an important determinant of primary productivity (Davy et al. 1976).

The objective of this research was to develop a simple model to estimate upland rangeland production using rainfall indexes (calculated from daily precipitation data) as predictor variables.

\footnotetext{
Journal Article 1512 of the New Mexico Agr. Exp. Sta., Las Cruces.

Manuscript accepted 30 August 1991.
}

\section{Description of Area}

The Sahel has a unimodal rainfall pattern, with the rainy season beginning as early as June and ending as late as mid-October in the pastoral zone. Most forage production occurs in the rainy season in the form of herbaceous annuals. The subsequent 8-9 month dry season is harsh for livestock because of the lack of green feed, low forage quality and, in some years, low forage quantity.

Sahelian herbaceous production exhibits extreme interannual variations. Average annual pasture production levels in the central pastoral zone of Niger from 1984 to 1987 varied from 8 to 388 $\mathrm{kg} \bullet \mathrm{ha}^{-1}$ north of $16^{\circ}$ north latitude and from 32 to $816 \mathrm{~kg}^{\circ} \mathrm{ha}^{-1}$ south of $16^{\circ}$ north latitude (Wylie et al. 1987).

Rainfall events in the Sahel tend to be high-intensity storms (Hoogmoed and Stroosnijder 1984) resulting from localized convection cells that exhibit high spatial variability. Estimated average storm cell size was 5 to $20 \mathrm{~km}$ along the wind direction (Davy et al. 1976). Year-to-year rainfall variation can differ from the mean by $50 \%$ in the Sahel and $100 \%$ in the southern Sahara.

The study area was the pastoral zone of central Niger, which is roughly square, with the towns of Tahousa, Tassara, Agadez, and Tanout located in each corner of the square (Fig. 1). The area includes 9 million ha with annual rainfall varying from $100 \mathrm{~mm}$ in the north to $400 \mathrm{~mm}$ in the south. Dominant ecological land systems in the southern half of the project zone are river-drained savannas and sand dune grasslands (Milligan 1982). These are dominated by annual grasses and forbs, primarily Aristida mutabilis Trin. \& Rupr., Cenchrus biflorus Roxb., and Indigofera spp. The scattered trees are primarily Acacia spp. and Balanites aegyptiaca Del.

Major ecological land systems in the northern part of the project zone are uniform savannas, and runoff and flood plains. Vegetation cover here is more sparse, with perennial grasses being more prevalent than in the south. Tree cover in the north is mostly Commiphora africana and Acacia spp.

\section{Methods}

\section{Biomass}

Upland sites with sandy soils were selected to represent the river-drained savanna and the sand dune grassland ecological land systems mapped by Milligan (1982). Rangelands that develop in these ecoregions are traditionally grazed during the 9-month dry season. The sites were sampled at the end of the growing season (late August-September) in 1980-1986.

Biomass was estimated by double-sampling (Cook and Stubbendieck, 1986 p. 245), using weighted least-squares regression analysis. Each site had 20 to 150 plots, with roughly $10 \%$ being clipped. Plot size varied among sites and years from 0.1 to $0.5 \mathrm{~m}^{2}$. Each pasture standing crop mean represented a 1-ha area, except for 6 sites at Ibecetene in 1985, which were only 0.5 ha. Sampling was usually conducted within existing rain gauge exclosures; however, if no suitable site was available at the rain gauge, and several exclosures or lightly grazed areas were available around the village, 


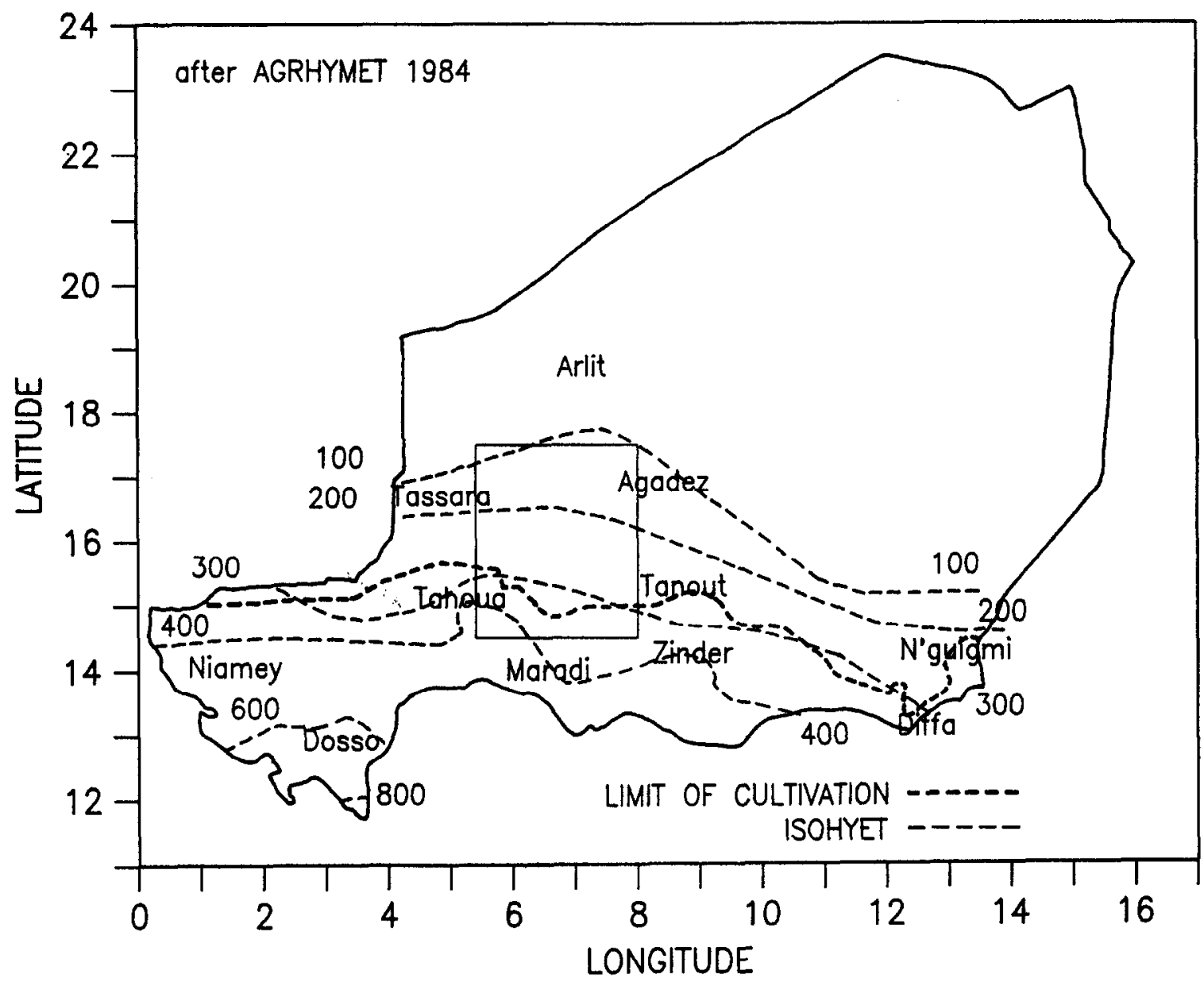

Fig. 1. Location of study area, mean annual isohyets (1951-1982), and the approximate limit of cultivation in the Republic of Niger.

sampling was in the 4 cardinal directions from villages. Plot cluster placement was random. Within each plot cluster, several plots were placed systematically. The number of clusters and plots per cluster varied among sites and years.

A single, pooled regression equation based on double sampling was established for each person estimating plot weights over the sampling period. These regression equations were then tested for possible differences in slopes and intercepts among sites (Neter et al. 1983 ; p. 285) to test site indicator variables and interaction terms. Sites found to have different slopes or intercepts were characterized by separate regressions.

\section{Precipltation}

Precipitation variables were generated from a Basic program, INTERVAL, which had the option to divide the rainy season into 2 periods based on calendar date. The output files generated by INTERVAL contained all the rainfall variables for the first period, second period, and the entire rainy season, respectively. The cutoff time between the early and later parts of the rainy season in INTERVAL was varied (15 Aug., 1 Sept., 10 Sept., and entire rainy season) to determine the usefulness of early rainy season precipitation to estimate end-of-rainy-season pasture standing crop. The rainfall variables produced by INTERVAL were grouped into 3 classes for rainfall-biomass model development: (1) minimal, (2) moderate, (3) extensive analysis of rainfall data.

\section{Minimum Analysis}

The only minimum analysis rainfall variable was the total daily rainfall summed for the rainy season in $\mathrm{mm}$. These data were used in the analyses.

\section{Moderate Analysis}

Effective rainfall was the rain index used to test moderate analysis of daily rainfall data. Effective rainfall was defined as the total daily rainfall in mm between minimum and maximum rainfall limits. Rainfall events that exceeded the maximum were counted as the maximum amount. Rain events below some minimum amount contribute insignificantly to herbage production because of high evaporative losses. On the other hand, large rainfall events exceeding some maximum amount can completely saturate the soil at the herbaceous plant rooting depth. Additional moisture above the maximum results in percolation of soil moisture below the rooting depth of herbaceous plants, as well as high amounts of surface runoff.

Effective rainfall was calculated using inputed minimum $(5,7$, and $10 \mathrm{~mm}$ ) and maximum rainfall limits $(30,40$, and $50 \mathrm{~mm})$. Appropriate effective rainfall limits were identified by selecting models with rainy-season-long and early-(up to 15 August) rainyseason effective moisture.

\section{Extensive Analysis}

A crude soil water model was developed within INTERVAL to calculate extensive rainfall analysis variables. The soil moisture model and its extensive rainfall variables were used to index rainfall amount and distribution. 
Soil water-holding capacity in the rooting zone of annual herbaceous vegetation, daily evapotranspiration and a crude root growth model were user-defined inputs into INTERVAL. INTERVAL allows soil water to increase with each rainfall event, up to the soil moisture-holding capacity in the rooting zone of herbaceous plants. The root growth model in INTERVAL is a linear regression, similar to that of Van Keulen et al. (1985), in which the user inputs the amount of rain available to germinating annual herbaceous plants (in $\mathrm{mm}$ ) as the intercept, $B O$, and a daily growth factor, the slope (BI), for each day the rooting zone was moist and conducive to plant growth. Root growth occurs up to a user-defined maximum root depth measured in $\mathrm{mm}$ of soil water.

For each day, the daily evapotranspiration amount was subtracted from the water stored in the rooting zone. The number of days when the rooting zone was moist and conducive to plant growth was called moist-days, and this variable was used as an index of rainfall quantity.

For extensive analyses of rainfall data, moist-days was the sole rainfall quantity variable. Two different sets of $B 0$ and $B 1$ terms were tested: $B 0=5 \mathrm{~mm}$ and $B 1=1.00$, and $B 0=7 \mathrm{~mm}$ and $B 1=1.50$. These root growth models allowed 35 and 22 moist days, respectively, to attain a rooting development sufficient to access the equivalent of $\mathbf{4 0} \mathrm{mm}$ of rainfall in soil water. For each of these 2 soil root growth models, 3 levels of daily evapotranspiration were tested: 2,4 , and $6 \mathrm{~mm} /$ day. These evapotranspiration rates were similar to those recorded by Cocheme and Franquin (1967), Davy et al. (1976), and Hiernaux (1984). Within each of these daily evapotranspiration rates, 3 different values for the maximum rooting zone or soil water capacity in mm of rainfall were tested: 30,40 , and $50 \mathrm{~mm}$, which roughly corresponded to the middle 2 groups of the 4 available soil water groups used by Davy et al. (1976).

Options available in INTERVAL include the subtraction of estimated runoff from the rainfall variables. The subroutine that estimates runoff from rainfall amount was taken from Penning de Vries and Djitéye (1982, p. 144). In addition, the daily evapotranspiration rate could be varied as a function of the amount of soil water available in the rooting zone and the age of the vegetation.

Using the soil water model above, the number of days soil water was not conducive to plant growth were also identified and called dry-days. Dry-days constitute a stress on plants, and should have a substantial negative effect on plant production, especially extended moisture stress periods. INTERVAL quantifies the number of consecutive days occurring in stress periods.

The rainfall distribution variables, dry-days and consecutive day-days, were calculated with varying input parameters. The input parameters were the number of consecutive dry-days needed to constitute a plant stress period (stress period), the cutoff date for stress period calculations (end date), and the number of moist-days needed to end or break a plant stress period (break). In general, these input parameters were similar to those used in Mali (Hiernaux 1984).

The rainfall distribution variables (consecutive dry-days and dry-days) were tested as possible additions to selected moist-days models. This was done with stepwise regression analysis considering the 2 rainfall distribution variables for the first part of the rainy season (up to the respective cutoff date), the latter part of the rainy season (after the cut off date) and the entire rainy season. The stress period calculation was done only until the number of moist-days exceeded the values input for the end date input parameter, 30 and 50 moist-days, respectively.

\section{Precipitation-Biomass Regression}

The precipitation variables and estimated biomass values for each site from 1980-1985 was used to establish regression relationships between biomass (dependent variable) and rain indices (independent variables calculated from respective input parame- ters). The regression analysis strategies employed were weighted least-squares and ordinary least squares using a natural logarithmic transformation. The weighting term used was the sampling variance of the respective biomass estimates.

The natural logarithmic transformations of the dependent variable was used because nonlinear increases in herbaceous growth have been monitored in the Sahel (Hiernaux 1984, Le Houéerou and Host 1977, Penning de Vries and Djitéye 1982, p. 166). Also plots of the data points indicated they conformed to a general form that is best explained by a logarithmic transformation of the dependent variable (Neter et al. 1983, p. 138). Residual plots of the models were used to assess linear trends and homogeneity of variances visually.

The most appropriate rainfall input parameters were determined by selecting input parameters that minimized the standard error of the regression estate. This was done for the 3 rainfall data analysis classes: (1) minimal, (2) moderate, and (3) extensive, employing both weighted and logarithmic models.

Models were evaluated by comparing the $80 \%$ confidence limits for predicted mean values of the different regression models. Because the models used different independent variables, the confidence intervals were plotted using actual versus predicted axes to facilitate comparisons. Comparisons of the best models from each of the 3 levels of rainfall analysis (minimal, moderate, and extensive) allowed selection of the weighted least squares and logarithmic models. Selected models from the 1980-1985 data set were then tested by determining if an independent data set, the 1986 biomass and rainfall variables, were contained in $95 \%$ confidence intervals for observations. Binomial probabilities were used to test if the number of observations within the confidence intervals warranted rejecting or accepting the model.

\section{Results and Discussion}

Pasture production regression analyses were separated and/or pooled in accordance with the extra sum of squares principle. In general, the adjusted $R^{2}$ values were acceptable with 5 having $R^{2}$ values less than 0.60 . Standard errors of the estimate, transformed by the weighting, were less than $40 \mathrm{~kg} \bullet \mathrm{ha}^{-1}$, except in 4 cases, 2 of which are from 1984, with Tabalak having the highest standard error of $91 \mathrm{~kg} \bullet \mathrm{ha}^{-1}$ in 1986.

Regression equations were pooled to provide an adequate number of clipped plots to represent each regression equation. However, 3 of the regression equations had fewer than 10 clipped plots and 1 had only 3 clipped plots.

Fifteen regression equations were used to convert average estimated plot weight per site to estimated equivalent air dry weights (Table 1). The column of $s$ combined is the sample standard deviation combined from both the regression and the mean estimated plot weight (Cook and Stubbendieck 1986 p. 247). Coefficients of variations $(\mathrm{CV})$ for pasture production means were generally less than $30 \%$. Raw data were not available for 2 sites in 1983, Inidi and Ranch North Dakoro (RND), so sampling standard deviations were estimated.

\section{Weighted-Least-Square Analysis}

The minimal analysis model with a cut off date of 15 August had the lowest standard error of the regression estimate. August is usually the wettest month, with the reproductive phenological stage for the dominant grass (Cenchrus biflorus) and other species photoperiodically triggered around mid-August.

Selected effective moisture minimum and maximum parameter values were compared with varying cutoff dates for moderate analysis model. There was a better fit with the 15 August cutoff date and 7 and 30 as minimum and maximum effective parameter 
Table 1. Pasture biomass estimates and statistics obtained with double sampling for each site 1980-1986.

\begin{tabular}{|c|c|c|c|c|c|}
\hline Name or number & Year & $\begin{array}{c}\mathbf{S}^{\prime} \\
\text { Combined }\end{array}$ & Mean & $(\mathrm{CV})$ & $\begin{array}{r}\text { Total } \\
\text { precip. }\end{array}$ \\
\hline & & (kg/ha) & $(\mathrm{kg} / \mathrm{ha})$ & & $(\mathrm{mm})^{2}$ \\
\hline ADDER & 1980 & 342 & 1,597 & $21.4 \%$ & 108 \\
\hline INIDI & 1980 & 90 & 861 & $10.4 \%$ & 116 \\
\hline RND & 1980 & 232 & 2,445 & $9.5 \%$ & 204 \\
\hline ADDER & 1981 & 264 & 340 & $77.7 \%$ & 121 \\
\hline INIDI & 1981 & 122 & 773 & $15.8 \%$ & 213 \\
\hline RND & 1981 & 94 & 709 & $13.3 \%$ & 235 \\
\hline GADABED & 1981 & 218 & 176 & $123.8 \%$ & 37 \\
\hline INIDI & 1982 & 491 & 548 & $89.5 \%$ & 78 \\
\hline RND & 1982 & 283 & 984 & $28.8 \%$ & 214 \\
\hline GADABED & 1982 & 987 & 1,939 & $9.7 \%$ & 98 \\
\hline INIDI & 1983 & $690^{3}$ & 1,153 & - & 226 \\
\hline RND & 1983 & $366^{3}$ & 221 & 一 & 118 \\
\hline INIDI & 1984 & 121 & 145 & $83.8 \%$ & 85 \\
\hline EKIN & 1984 & 29 & 329 & $8.8 \%$ & 58 \\
\hline AKAB & 1984 & 24 & 429 & $5.7 \%$ & 83 \\
\hline IBEC HQ & 1984 & 14 & 724 & $1.9 \%$ & 189 \\
\hline T. TABA & 1984 & 71 & 314 & $12.4 \%$ & 62 \\
\hline ADDER & 1985 & 35 & 400 & $8.8 \%$ & 136 \\
\hline INIDI & 1985 & 139 & 785 & $17.8 \%$ & 163 \\
\hline RND & 1985 & 269 & 2,668 & $10.1 \%$ & 256 \\
\hline GADABED & 1985 & 349 & 3,103 & $11.2 \%$ & 257 \\
\hline AKAB & 1985 & 23 & 809 & $2.8 \%$ & 162 \\
\hline IBEC HQ & 1985 & 915 & 1,039 & $88.0 \%$ & 234 \\
\hline T. TABA & 1985 & 39 & 314 & $12.4 \%$ & 67 \\
\hline 6.2 & 1985 & 1,026 & 288 & $356.2 \%$ & 268 \\
\hline 3.6 & 1985 & 48 & 819 & $5.8 \%$ & 256 \\
\hline 5.4 & 1985 & 154 & 853 & $18.1 \%$ & 234 \\
\hline 6.6 & 1985 & 54 & 823 & $6.5 \%$ & 251 \\
\hline 1.4 & 1985 & 167 & 834 & $20.0 \%$ & 250 \\
\hline 1.2 & 1985 & 359 & 904 & $39.8 \%$ & 246 \\
\hline T. TABO & 1985 & 55 & 1,297 & $4.2 \%$ & 138 \\
\hline TABALAK & 1985 & 18 & 731 & $2.4 \%$ & 314 \\
\hline INIDI & $1986^{4}$ & 45 & 868 & $5.2 \%$ & 298 \\
\hline RND & $1986^{4}$ & 75 & 199 & $37.8 \%$ & 167 \\
\hline AKAB & $1986^{4}$ & 29 & 619 & $4.6 \%$ & 270 \\
\hline IBEC HQ & $1986^{4}$ & 36 & 895 & $4.0 \%$ & 321 \\
\hline TABALAK & $1986^{4}$ & 579 & 3,117 & $18.6 \%$ & 365 \\
\hline
\end{tabular}

'Sampling standard deviation (Cook and Stubbendieck, 1986 p. 247).

2Total precipitation excludes early rains that occurred before the surviving germination occurred.

${ }^{3}$ Raw biomass data were not available for these sites. The $s$ combined was estimated by averaging the $x$ combined for the closest larger and smaller biomass values.

4The 1986 pasture production estimates were used only to test the models developed.

Table 2. Minimum and maximum early effective moisture limits and cutofi dates effects on standard errors using a linear weighted least-squares model and a logarithmic model.

\begin{tabular}{lcccc}
\hline \hline Minimum & Maximum & Cutoff & $\begin{array}{c}\text { Weighted } \\
\text { standard } \\
\text { error }\end{array}$ & $\begin{array}{c}\text { Logarithmic } \\
\text { standard } \\
\text { error }\end{array}$ \\
\hline & & & $\ldots \ldots--\mathrm{kg} / \mathrm{ha}^{-1} \ldots \ldots---$ \\
5 & 40 & 15-Aug & 3.87 & 0.67 \\
5 & 40 & 01-Sep & 4.40 & 0.65 \\
5 & 40 & $10-$ Sep & 4.41 & 0.64 \\
5 & 40 & 30-Sep & 4.52 & 0.65 \\
5 & 50 & 15-Aug & 3.99 & 0.68 \\
5 & 50 & 01-Sep & 4.47 & 0.66 \\
5 & 50 & 10-Sep & 4.40 & 0.64 \\
5 & 50 & 30-Sep & 4.51 & 0.66 \\
7 & 30 & 15-Aug & 3.79 & 0.68 \\
7 & 30 & 01-Sep & 4.39 & 0.66 \\
7 & 30 & 10-Sep & 4.45 & 0.64 \\
7 & 30 & 30-Sep & 4.60 & 0.66 \\
10 & 30 & 15-Aug & 4.56 & 0.65 \\
10 & 30 & 01-Sep & 4.56 & 0.65 \\
10 & 30 & 10-Sep & 4.58 & 0.63 \\
10 & 30 & 30-Sep & 4.64 & 0.65 \\
\hline
\end{tabular}

values (Table 2). This implies that rainfall events of less than $7 \mathrm{~mm}$ and greater than $30 \mathrm{~mm}$ do not contribute significantly to herbage standing crop.

For early and entire season rainfall extensive analysis weighted models, the root depth model of $B 0=7$ and $B 1=1.50$ had relatively low standard errors of estimates and were selected. Daily evaporation rate had greater effects on the weighted standard errors of estimates than soil water-holding capacity. An evaporation rate of $4 \mathrm{~mm} \cdot$ day $^{-1}$ and a soil water capacity of $40 \mathrm{~mm}$ were selected for analyses with different cutoff dates.

For this model, as with weighted least-squares models using effective rainfall and total rainfall, the weighted standard error of the estimate was lowest using the 15 August cutoff date. Using the weighted exensive model with selected input parameters given above, the lowest standard error of the estimates was attained with no runoff estimation and a constant evapotranspiration rate. The estimation of percent runoff as a linear function of daily rainfall amount did not improve the model. Perhaps the selection of upland sites with sandy to sandy loam soils minimized runoff effects, or runoff is more strongly related to rainfall intensity rather than amount (which was used here). The oversimplification of the factors affecting the fluctation of daily evapotranspiration rates added to the model's variability.

\section{Temporal Distribution}

Some distribution variables were significant for particular soil moisture model input parameter variations with the selected extensive weighted model (Table 3 ). The minimum weighted standard error of the estimate (3.44) was obtained using a 15-day period with 3 consecutive moist-days to break the plant stress period.

Table 3. Linear weighted least squares regression results with additional significant independent variables to the moist days independent variable.

\begin{tabular}{llll}
\hline \hline $\begin{array}{l}\text { Stress } \\
\text { period } \\
\text { (days) }\end{array}$ & $\begin{array}{l}\text { End Independent } \\
\text { date variables }\end{array}$ & $\begin{array}{l}\text { Weighted } \\
\text { standard } \\
\text { error of } \\
\text { estimate }\end{array}$ & $\begin{array}{c}\text { Pearson } \\
\text { correlation } \\
\text { coefficient }\end{array}$ \\
\hline 7 & 30 moist-days & 3.71 & \\
15 & 30 moist-days, strl ${ }^{3}$ & 3.47 & -0.36 \\
15 & 30 moist-days, strt & 3.52 & -0.08 \\
30 & 30 moist-days & 3.71 & -0.52 \\
7 & 50 moist-days, strl & 3.51 & -0.31 \\
7 & 50 moist-days, strt & 3.50 & -0.36 \\
15 & 50 moist-days, strl & 3.44 & -0.10 \\
15 & 50 moist-days, strt & 3.46 & \\
30 & 50 moist-days & 37.1 & \\
\hline
\end{tabular}

1Pearson correlation coefficient between independent variables.

${ }^{2}$ Moist days variable up to the cutoff date.

3Stress period variable, consecutive dry days up to the cutoff date.

4 Stress period variable up to the number of moist days determined by the rainfall distribution input parameter, end date.

The 15 August cutoff date was used for both independent variables. Pearson correlation coefficients between the independent variables were small. A condition number indicated multicollinearity was not a problem for this model (Belsley et al. 1980).

One would expect the consecutive dry-days variable to be negatively correlated to pasture production; however, in this model, it was positive:

$$
Y+233.84+18.32 X_{1}+4.48 X_{2}
$$

where $X_{1}=$ moist days

$$
\begin{aligned}
X_{2} & =\text { consecutive dry days } \\
\hat{Y} & =\text { estimated biomass }(\mathrm{kg} / \mathrm{ha})
\end{aligned}
$$

where $\mathbf{Y}$ is the biomass estimate in $\mathrm{kg} \bullet \mathrm{ha}^{-1}$. Stress periods for consecutive dry-days were a minimum of only 15 dry-days. Smaller 


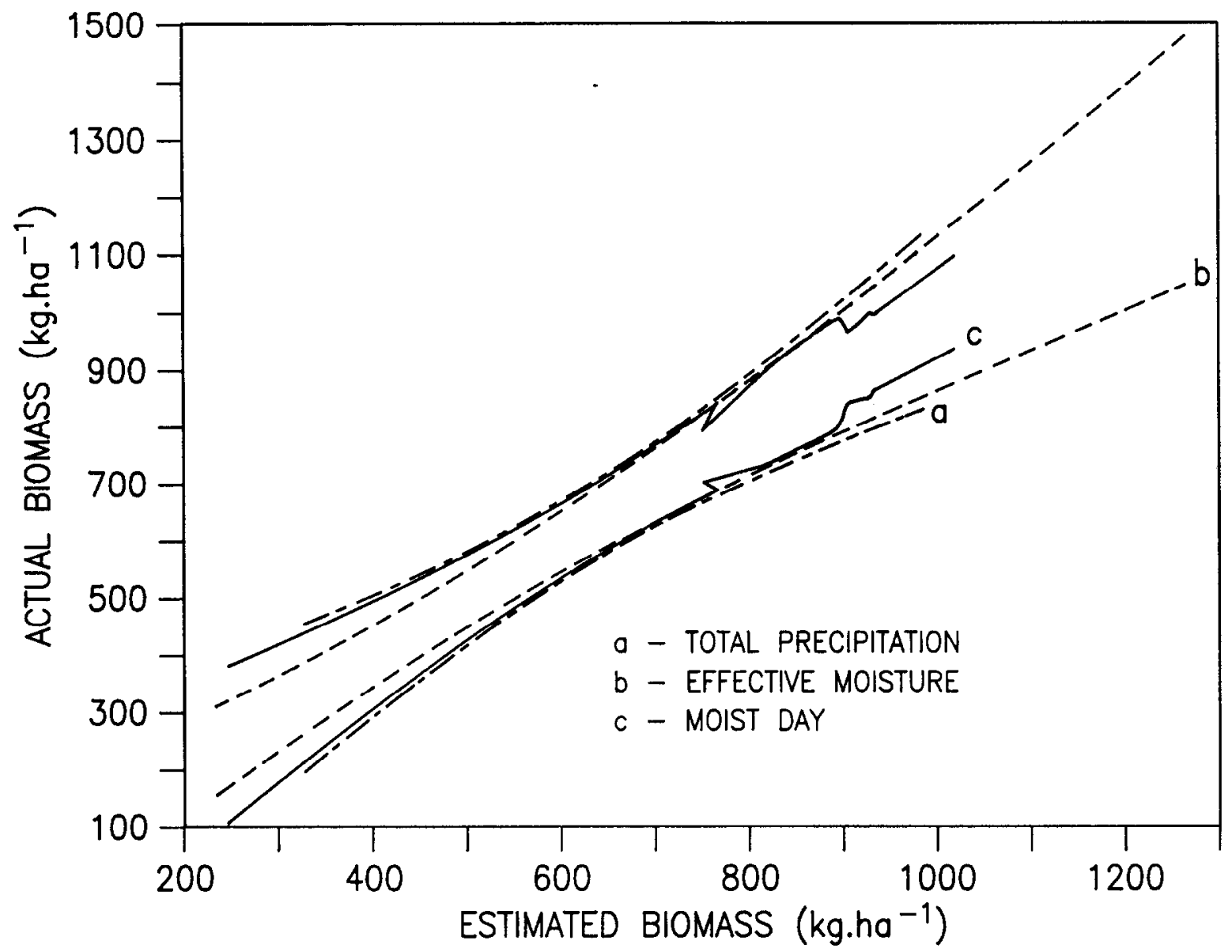

Fig. 2. Comparison of best weighted least squares models $80 \%$ confidence intervals for mean values.

rainfalls could occur within these 15 days. Three moist-days were needed to break a plant stress period. Using the daily evapotranspiration rate of $4 \mathrm{~mm}$ used in this model, rainfall events of up to 11 mm could occur without breaking the plant stress period. The positive coefficient for consecutive negative days may be indicating that plant efficiency of soil moisture use increases under moisture deficits. Stomatal closure under moisture stress reduces daily evapotranspiration rates and increases water use efficiency (Van Keulen et al. 1985). Thus, the constant daily evapotranspiration rate used in this model underestimated biomass levels when conditions are moderately xeric. In addition, widely spaced, large rainfall events would favor deep root development, improving plant moisture availability.

\section{Comparison of Better Models}

The $80 \%$ confidence intervals for mean values showed little difference in the middle section of the respective regressions (Fig. 2). At the extreme ends of the regressions, however, confidence limits could be separated. The widest confidence limits were for total precipitation. The moderate-width confidence interval was for the moderate analysis of rainfall, or the effective moisture variable. The best extensive rainfall analysis model was a multiple regression including moist-day and consecutive dry-day as independent variables. These confidence limits are the narrowest at low and high biomass estimates. The peculiar fluctuations in these confidence limits at higher biomass values are the result of the effect of the second independent variable.

For a drought early warning system, the importance of accuracy in the extremely high and low biomass values should not be underestimated. The extensive analysis of rainfall model was the selected model for estimating pasture production with a linear weighted least squares-analysis.

\section{Testing Selected Model}

The plotting of the weighted $95 \%$ confidence limits was done on the transformed data set. This was necessary because of the high variability of the respective biomass error terms for a given predicted biomass range. In the transformation process to simulate a weighted least-squares analysis, the divisor of both the independent and dependent variables is the square root of the weighting term (Neter et al. 1983, p. 171). In this case, the divisor is the biomass sampling standard deviation from Table 1 .

The $95 \%$ confidence intervals for observations were plotted with the independent test values (1986) after weight transformation. Of the 5 test values, 2 were outside the confidence intervals. A test data value that was on the lower confidence interval line was from the North Dakoro Ranch, and was of questionable value because of high human trampling and traditional end of rainy season herbage removal. The herbaceous biomass within the exclosure at the time of sampling appeared lower than that of adjacent grazed pastures. The fact that this site was overestimated by the model is not surprising. However, the second outlier, which occurred at a higher estimated biomass value, was well below the confidence interval. This data point is the Akabounou pump station. No ecological anomalies were observed during sampling. Using the $95 \%$ confidence intervals for an observation, we expect from binomial probabilities roughly $20 \%$ of the 5 test values to lie outside the confidence intervals. In this case, 1 value out of $5(20 \%)$ was inexplicably outside the confidence intervals. This model is acceptable, but with this low number of test observations, it was accepted with caution, 


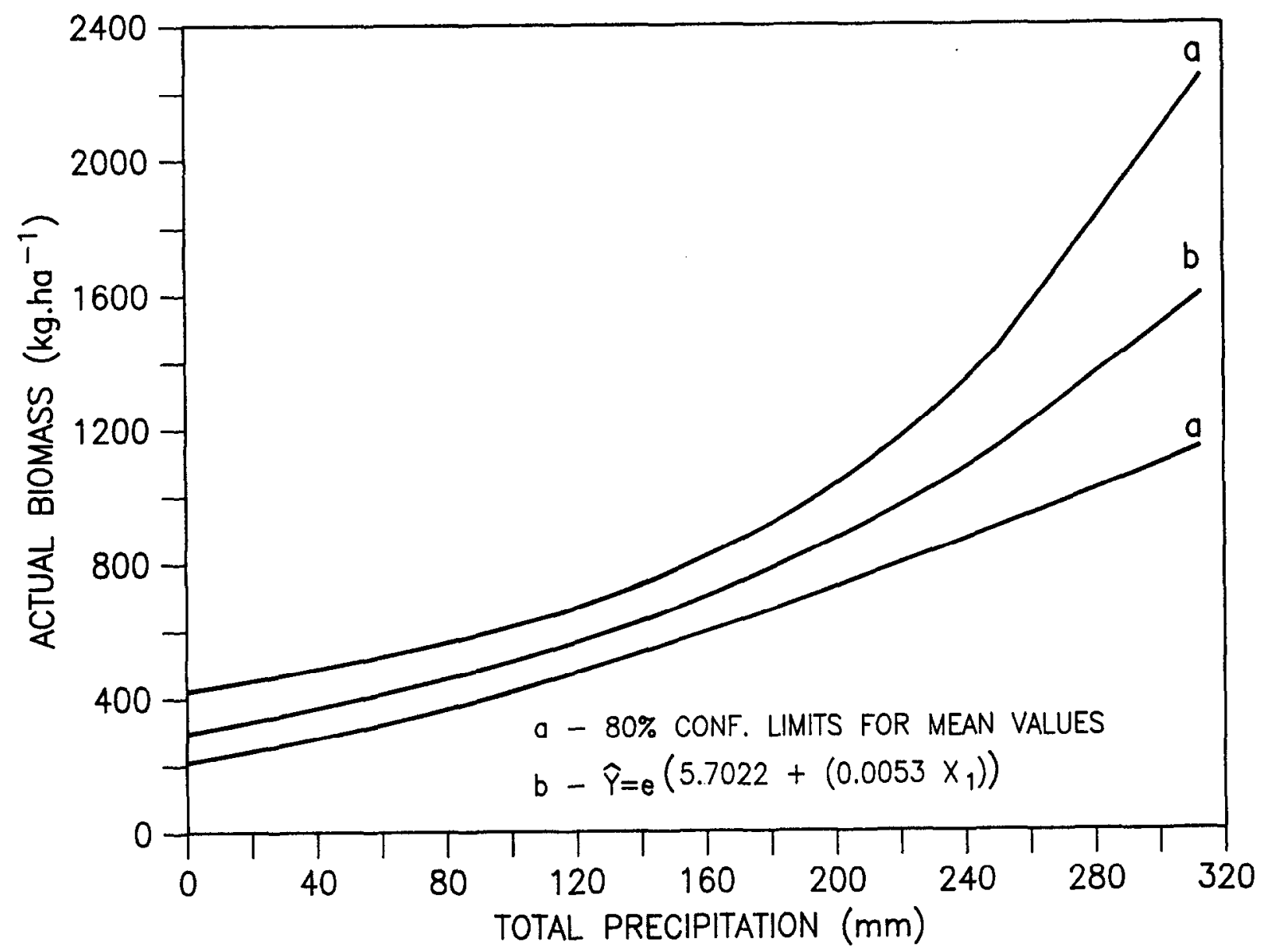

Fig. 3. The $80 \%$ confidence interval for mean values for the weighted molst day and consecutive dry-day model.

and should be tested with additional data in the future.

This model allows the estimation of end of rainy season pasture production using rainfall data only up to the mid- Liny season, August 15. This could be useful predicting impending pasture deficits and surpluses in the pastoral zone of Niger midway through the rainy season.

The adjusted $R^{2}$ for this model was 0.64 , and the weighted standard error of the estimate was 3.4. No apparent lack of fit or heterogeneity was observed in the residuals.

This model would be applied to obtain herbage stand crop estimates to represent upland sites with sandy soils for regions within the pastoral zone. To obtain a regional biomass estimate, data from several rain gauges would be used. Thus, the moist-days and consecutive dry-days from each rain gauge would be averaged, then the averages would be entered into the regression equation. The $80 \%$ confidence intervals for mean values seem appropriate for this application. Figure 3 indicates pasture production levels could be separated using roughly $200 \mathrm{~kg} /$ ha incremented production means.

The problem with weighted analysis is that the error term of the biomass value should be known. In some instances, estimated error term values can be used. Biomass sampling standard deviations used in this study were erratic and were not a function of the independent variables; consequently, biomass error terms would be difficult to estimate.

\section{Logarithmic Analysis}

\section{Minimal Analysis of Rainfall}

For the logarithmic model, total precipitation was most strongly associated with herbage standing crop using a cutoff date of 10
September. A logarithmic model would be appropriate to estimate exponential herbaceous growth that occurs in the Sahel until the above ground production is about $1,000 \mathrm{~kg} \cdot \mathrm{ha}^{-1}$ (Penning de Vries and Djitéye 1982, p. 166).

\section{Moderate Analysis of Rainfall}

Comparisons of the standard error of the estimates for selected input effective rainfall parameters and cutoff date using a logarithmic model are presented in Table 2. For the logarithmic model, it appears the cutoff date of 10 September, generally, has the lower standard error of the estimate. The lowest standard error of the estimate was obtained with a minimum effective moisture limit of 10 and a maximum of 30 .

\section{Extensive Analysis of Rainfall}

The root depth model of $B O=5$ and $B 1=1.00$ had a lower minimum standard error of estimate. The most appropriate logarithmic model with an 15 August cutoff date had rainfall input parameters of $50 \mathrm{~mm}$ for soil water capacity, and a daily evapotranspiration of $6 \mathrm{~mm}$.

Using the most appropriate logarithmic input parameters determined the cutoff date was varied (15 August, 1 Sept., 10, Sept. and entire season). The logarithmic model had a smaller standard error with a cutoff date of 10 September, as was the case with the logarithmic models for total precipitation and effective moisture. None of the distribution variables contributed significantly to this model.

\section{Comparison of Better Models}

The comparison of the $80 \%$ confidence intervals for mean values 


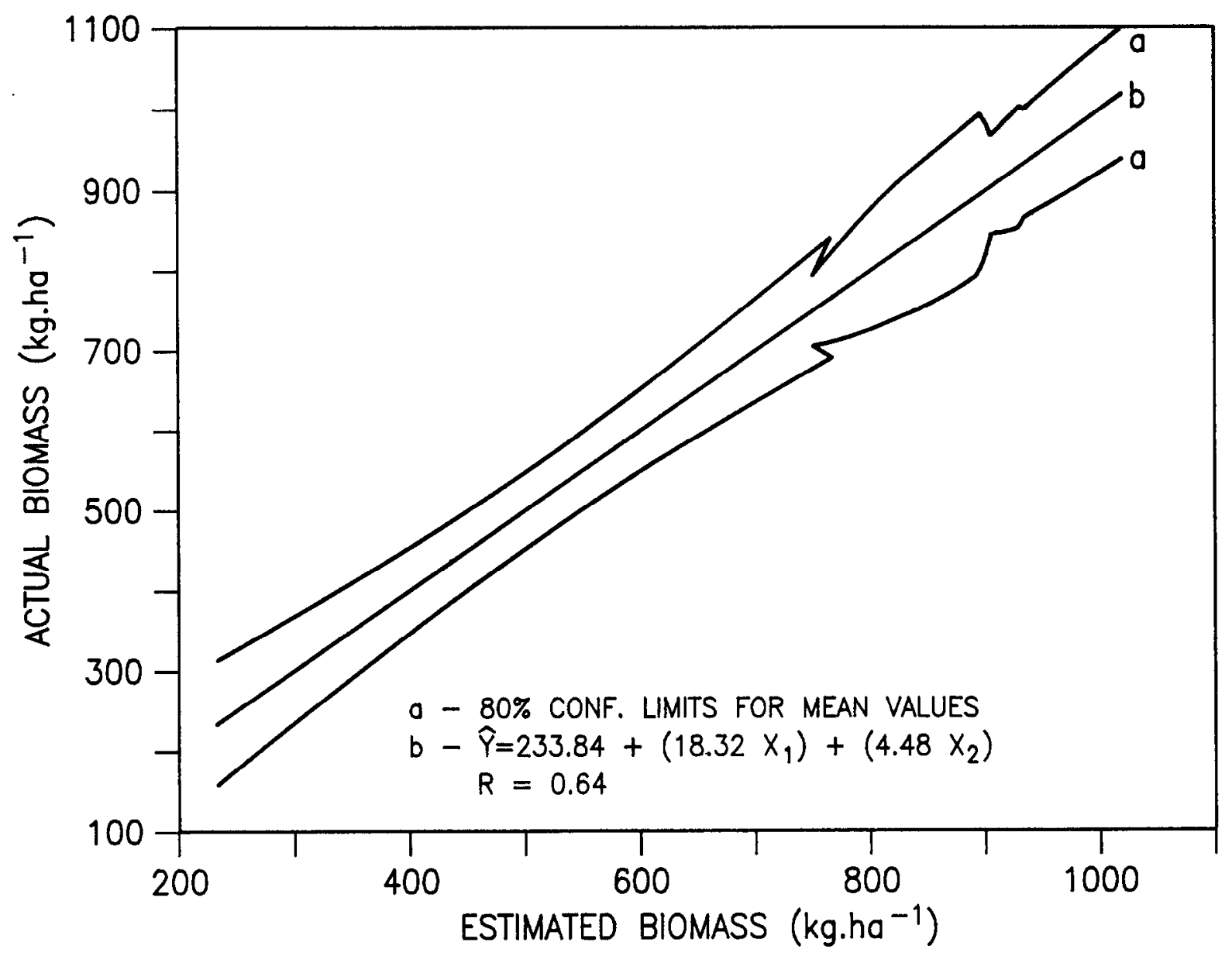

Fig. 4. The $80 \%$ confidence intervals for mean values for the best logarithmic model using total precipitation.

for best logarithmic models in each rainfall analysis category showed that even at the extreme estimated biomass values, differences in accuracy of the models were nominal.

The lack of a substantial difference in the confidence interval widths indicates little precision was gained by using a logarithmic model with moderate or extensive analysis of the rainfall data. Therefore, use of total rainfall seems to be appropriate for the logarithmic model.

\section{Testing Selected Models}

The 1986 test data were plotted with the $95 \%$ confidence intervals for observations of the selected logarithmic model. The North Dakoro Ranch test data point again was low, as expected, but was still within the confidence intervals. The other 4 test data points were all well within the confidence intervals.

The $80 \%$ confidence intervals for mean values (Fig. 4) shows that production classes could be separated at about $200 \mathrm{~kg} \cdot \mathrm{ha}^{-1}$ intervals for biomass estimates less than $800 \mathrm{~kg}^{\circ} \mathrm{hg}^{-1}$. Above 800 $\mathrm{kg} \cdot \mathrm{hg}^{-1}$, the confidence bands increase the interval spacing to 400 $\mathrm{kg} \cdot \mathrm{hg}^{-1}$ or more.

Model coefficients were:

$$
\begin{aligned}
P= & e^{[5.702236+(0.005338 X 1)]} \\
\text { where } & Y=\text { the estimated biomass }(\mathrm{kg} / \mathrm{ha}) \\
X_{1} & =\text { the total precipitation }(\mathrm{mm})
\end{aligned}
$$

The adjusted $R^{2}$ was 0.29 , and the logarithmically transformed standard error of the estimate as 0.65 . The residual plot of the transformed data show no apparent lack of fit or heterogeneity of the variance.
Using the 10 September cutoff date should include the bulk of the rainy season in the pastoral zone. This model is simple and appears to give moderately precise estimates of end of rainy season production levels on rainfall throughout the bulk of the rainy season.

\section{Conclusions}

Both selected models appear to have possibilities for application. For early warning of drought conditions, even before the completion of the rainy season, the selected weighted-least-squares model could be applied. The government of Niger could predict regional end of rainy season biomass levels by mid-August. However, this model requires the use of a computer program (INTERVAL) to generate rainfall indexes, moist-days, and consecutive dry-days. Average moist-days and consecutive dry-days indexes should be averaged across 20 or more rain stations within the region for which the biomass estimate is to be made. This model would require daily rainfall data from the pastoral zone of Niger, which is available daily for selected meteorological stations. However, additional rain stations exist that may require regional or even site visits to acquire data. Other disadvantages of this model are: (1) it requires estimates of biomass error terms (one could estimate biomass with a CV of $30 \%$ ), and (2) that the test of this model was only marginally acceptable.

The logarithmic model that was selected does not require daily precipitation data, only total precipitation prior to 10 September. This is advantageous because some historical rainfall data sets are only available in monthly or 10-day totals, not in daily amounts. The logarithmic model also does not require a computer program 
to generate the total rainfall index. These factors make this model appealing for estimating historical biomass levels within the pastoral zone of Niger. The mean total precipitation from 20 or more rainfall stations should be used for this model when estimating biomass levels. Problems with the selected logarithmic model include widening of the confidence intervals for biomass levels above $800 \mathrm{~kg} \bullet \mathrm{hg}^{-1}$ and total rainfall index accounted for less than $30 \%$ of the variation in biomass levels, indicating relatively low predictive power of the model.

\section{Literature Cited}

Agrhymet Programe. 1984. Ten day regional agrometerological bulletin (May-October 1984). Centre Regional de Formation et d'Application en Agrometerologie et Hydrologie Operationelle, Niamey, Niger.

Belsey, D.A., E. Kuh, nd R.E. Welsh. 1980. Regression diagnostics: infuential data and sources of collinearity. John Wiley \& Sons, N.Y.

Cocheme, J., and P. Franquin. 1967. An agroclimatology survey of a semiarid area in Africa south of the Sahara. Tech. Note 86, WMO-210. TP.110. World Meteorological Organization, Geneva.

Cook, C.W., and J. Stubbendieck (eds.). 1986. Range research: basic problems and techniques. Soc. Range Manage. Denver, Colo.

Davy, E.G., F. Marrei, and S.I. Solomon. 1976. An evaluation of climate and water resources for development of agriculture in the SudanoSahelian zone of West Africa. Spec. Environ. Rep. 9, W-459. World Meteorological Organization, Geneva.

Hiernaux, P. 1984. Distribution des pluies et production herbacee au sahel: úne methode empirique pour caracteriser la distribution des precipitations journalieres et ses effets sur la production herbacee, premiers resultats acquis dans le sahel maien. ILCA Programme document N AZ 98. Feb.
Le Houérou, H.N., and C.H. Hoste. 1977. Rangeland production and annual rainfall relations in the Mediterranean basin and in the African Sahelo-Sudanian zone. J. Range Manage. 30:181-189.

Hoogmoed, W.B., and L. Stroosnijder. 1984. Crust formation on sandy soil in the Sahel. I. Rainfall and infiltration. Soil and Tillage Res. 4:5-23.

Justice, C.O., and P.H.Y. Hiernaux. 1986. Monitoring of grasslands of the Sahel using NOAA AVHRR data: Niger 1983. Int. J. Remote Sensing 7:1475-1497.

Van Keulen, H., H. Breman, J.J. van der Lek, J.W. Menke, J. Stroosnijider, and P.W.J. Uithol. 1985. Prediction of actual primary production under nitrogen limitation. In: $\mathrm{N}$. de Ridder et al. Proc. of ILCA-AROCABO workshop. ARO, Bet Dagan, Israel.

Milligan, K. 1982. Aerial survey of humane, livestock, and environmental conditions in a central region of the pastoral zone of Niger. ILCA. Final Report. March.

Neter, J., W. Wasserman, and M.H. Kutner. 1983. Applied linear regression models. Richard D. Irwin, Inc. 11 .

Onwordi, I. 1989. Drought in the Sahel. Camel Express (Friends of Niger) Edition Il. 406-6th St. SE, Washington, D.C.

Sollod, A.E. 1990. Rainfall, biomass and the pastoral economy of Niger: assessing the impact of drought. J. Arid Envir. 18:97-107.

Penning de Vries, F.W.T., and M.A. Djitéye. (eds.). 1982. La productivité des pâtuarages sahéliens, une étude des sols, des vévétations et de 1 exploitatin de cette ressource naturelle. Centre for Agr. Publ. Doc., Wageningen.

Wheeler, D.L. 1988. Field workers collect data for early warnings of famine in sub-Saharan Africa. Cronic. of Higher Ed. A5. 23 March.

Wylie, B., J. Harrington, Jr., B. Maidagi, and I. Denda. 1987. Pasture production in the central and eastern pastoral zones of Niger. Early Warning System Preliminary Report, Integrated Livestock Production Project (Niger/Tufts/USAID). Dec. 